\title{
Meandering the mine field of social media
}

\section{Introduction}

You can pick your social media platform on any night of the week. I'm not much into naming them specifically because that's not what this segment is about. Having worked in a trauma ER for multiple years as well as $20+$ years on nights, at the end of your shift you all need a place that is a safe haven to decompress and vent once in a while, doing what we do at odd hours of the night.

Unfortunately, I've been horrified to witness and observe innumerable travesties at the hands of our so called "professionals" in these forums. Now I'm not talking about the self-made meme's or humorous stories that are posted anonymously. As previously stated, you need a place to hang loose once in a while and those activities are not the focus of this editorial. I've been unfortunate to have witnessed legitimate cries for help from individuals running polysomnographs who haven't the slightest idea on to how professionally/properly ask for help. (i.e. from blatant HIPPA violations, to obscene "selfies" of ID wearing employees defacing the CEO's parking space, ranging from ignorance to just plain dangerous healthcare practices with patient lives at stake).

Having seen a patient die in a lab because staff didn't understand what they were doing, my motivation as an educator and instructor in the field for the last 3 decades eventually lead to my involvement with setting standards in one our professional societies. At the urging of multiple educators in our field, it's time to address the severe lack of training and unprofessionalism in our profession.

Example 1: Does anyone know what this EKG is? Now I've seen examples of ventricular bigeminy (or wide complex bigeminy if you want to get more specific), apparent BBB (bundle branch block), and 7-10 beat runs of wide complex tachycardia posted in multiple forums with technicians asking for help in identifying their posted arrhythmias. Followed by a variety of responses from fellow technicians, who by nature are willingly attempting to help each other out, it becomes clear to the educated that $80 \%$ of the responses/comments are incorrect. Thus confusing the original question asked, it often turns into a debate or a crass conversation that ends in a quote like, "Oh well, that's not my job anyways-I'll leave it for the day shift to score!"

Now I've attempted to help educate those in need when requested to do so on multiple occasions, only to be chastised by the group that night and proven to be correct the next day when the MD has confirmed my interpretation. I was trained as an educator to note the following:

i. Anytime giving an "interpretation" of an EKG, I preface it by, "With the limitations of a single lead EKG run during the study, at epoch \#XXX, there appears to be a run of...." You can't diagnose dysrhythmias via a single lead but you can save a patient's life! I myself had a patient throw a six second sinus arrest about 2hours into his study and called my MD who responded, "keep an eye on it and let me know if happens again." Surely enough 3hours later he had a 15 second run of sinus arrest which I verified by bumping up the amplitude in the EMG channels and saw the same thing.
Volume 3 Issue 2 - 2016

\author{
Stephen Tarnoczy \\ Editorial Review Member at MedCrave-Journal of Lung, \\ Pulmonary and Respiratory Research New Haven, Quinnipiac \\ University, USA
}

Correspondence: Stephen Tarnoczy, Editorial Review Member at MedCrave-Journal of Lung, Pulmonary and Respiratory Research New Haven, Connecticut Higher Education, Quinnipiac University, Email starnoczy@yahoo.com

Received: April 09, 2016 | Published: April 21, 2016

With another call to my MD he asked, "what stage of sleep is he in? "REM," I responded. "Wake the patient at 6am and tell him not to leave the lab until I get there!" 4hours later the patient was in a cardiologists office and scheduled that afternoon for a pacemaker to Rx his REM related sinus arrest.

ii. An EEG is posted with a well-defined rhythm lasting 5-6seconds only, unilateral to a central lead. Again the group responds with artifact, the lead or reference is on an artery, delta waves, etc. I tried to help the tech out by replying, "look at your other leads, has the patient been asleep less than 15minutes?" With an affirmative reply, I said, 'It's most likely a Mu rhythm", and gave them a link to similar examples so they could learn from it.

Now those are only (two) of 25 examples I've set aside for teaching purposes in my classes to show the lack of motivation by current technologists to do the job right, as well as the lack of educational resources provided to them at night. Often I hear things such as:
i. I called my medical director and he never responds
ii. We have no policy for that
iii. It's not my job
iv. We don't have any reference books in our labs

The problem goes far beyond the poorly lacking educational foundation these individuals have received; the time for an entry level A.S. is long overdue. The problem goes far beyond technicians being provided an unsafe work environment. The problem goes far beyond the credentialing bodies offering a lower credential such as a CPSGT, when in fact in 2006 they should have been raising the bar instead responding to the MD's request for a lower standard so they could run Medicaid patients. (As I was there in Seattle when I HEARD THE REQUEST MADE). 
I truly believe that most individuals want to do the right thing and are seeking answers to their questions but are not given a venue in which to properly be educated. Please understand, this is by no means a criticism of the administrators of the social media forums as it is nearly impossible to be available $24 / 7,365$ days a year. Their forums provide multiple educational formats for technicians to share tips/ tricks of the trade, as well as a venue to have a chuckle or two at shift's end. The focus needs to be on the patient and having an appreciation for what you are doing with your patient. I see to many techs take credit for "saving lives for a living" and in the same minute praising GOOGLE images for helping them identify an EKG.

It's clear the educational bar needs to be raised before something horrible happens to someone because they were put in a situation to fail because they were not properly educated. Now I know this a hot button topic, and I'm often criticized in my talks and lectures for putting things out there the way they are. However, having resuscitated a patient who eventually died because the RPSGT ignored the RRT clinical instructor, I myself couldn't sleep soundly during the day anymore if I just stood by the sidelines over the past year observing the cries for help and letting the field be aware of the great need to properly care for their night time staff.

\section{Acknowledgements}

None.

\section{Conflict of interest}

The author declares no conflict of interest. 